\title{
Factors associated with time to sputum culture conversion of rifampicin-resistant tuberculosis patients in Klaipeda, Lithuania in 2016-2019: a cohort study
}

\author{
Saulius Diktanas ${ }^{1}$, Oleksandr Korotych ${ }^{2}$, Yuliia Sereda ${ }^{2}$, Ogtay Gozalov ${ }^{2}$, Olga Rubcova ${ }^{1}$, Jay Achar ${ }^{3,4}$ \\ ${ }^{1}$ Republican Klaipeda Hospital, Tuberculosis branch, Klaipeda, Lithuania; ${ }^{2}$ World Health Organization, Regional Office for \\ Europe, Copenhagen, Denmark; ${ }^{3}$ Department of Global Public Health, Karolinska Institutet, Stockholm, Sweden; \\ ${ }^{4}$ Department of Medical Epidemiology and Biostatistics, Karolinska Institutet, Stockholm, Sweden
}

\begin{abstract}
Correspondence: Saulius Diktanas, Republican Klaipeda Hospital, Tuberculosis Branch, Klaipeda, Lithuania.

Tel. +370.61300656 .

E-mail: saulius.diktanas@kal.lt

Key words: Predictors; culture; conversion; multidrug-resistant; tuberculosis.

Acknowledgements: The authors thank the secretariat of the European TB Research Initiative (ERI-TB) at the WHO Regional Office for Europe for organizing the Structured Operational Research Training (SORT-TB) for eastern European countries supported by the USAID-WHO regional partnership project to End TB in eastern Europe. SORT-TB curriculum was an adaptation of the UNICEF/UNDP/World Bank/WHO Special Programme for Research and Training in Tropical Diseases (TDR) SORT IT course (https://www.who.int/tdr/capacity/strengthening/sort/en/) to the eastern European context.
\end{abstract}

Contributions: SD, JA, OK, conceived study aims. All authors participated in the design, discussion of the results interpretation, read, edited, and agreed with the decision to submit the final version of the paper; SD, data collection and reference reviews; YS, analysis design and execution; SD, OK, JA, first draft of the manuscript; YS, OG, OR, substantial revisions to the initial version of the manuscript.

Conflict of interest: The authors declare no conflict of interest.

Funding: First author received funding by Janssen Lithuania for travel to attend SORT-TB workshops, where research protocol for the study was developed. The funding body had no role in study design, data collection and analysis, decision to publish, or preparation of the manuscript.

Ethics approval: Local ethical approval was granted by Republican Klaipeda Hospital Medical Ethics Committee and exemption from an ethics review was also received from the World Health Organization Research Ethics Review Committee based in Geneva, Switzerland (ERC.0003313/11.03.2020). A waiver of informed consent was granted by ethics review bodies, as the study collected and analysed deidentified routine recording and reporting data.

Received for publication: 10 July 2020.

Accepted for publication: 11 August 2020

OWorld Health Organization 2021.

All rights reserved. The WHO Regional Office for Europe has granted the Publisher permission for the reproduction of this article.

Licensee PAGEPress, Italy

Monaldi Archives for Chest Disease 2021; 91:1675

doi: 10.4081 /monaldi.2021.1675

Open access statement: In accordance with WHO's open-access publication policy for all work funded by WHO or authored/co-authored by WHO staff members, the WHO retains the copyright of this publication through a Creative Commons Attribution IGO licence (http://creativecommons.org/licenses/by/3.0/igo/legalcode) which permits unrestricted use, distribution and reproduction in any medium provided the original work is properly cited.

\begin{abstract}
The global proportion of successful treatment outcomes of Multidrug-Resistant/Rifampicin-Resistant Tuberculosis (MDR/RR-TB) remains unacceptably low. Time to culture conversion is important in making treatment-related decisions and is used as an interim predictor of pulmonary MDR/RR-TB treatment success. No previous studies have been conducted to assess determinants of time to culture conversion for MDR/RR-TB patients in Lithuania. Secondary analysis of data of culture-positive MDR/RR-TB patients, treated in Republican Klaipeda Hospital between $1^{\text {st }}$ July 2016 and $1^{\text {st }}$ July 2019 was performed. Culture conversion was defined as two consecutive negative cultures on solid media submitted at least 30 days apart. Factors associated with culture conversion were estimated by crude and multivariable Cox regression accounting for competing risks. In total, 115 consecutive patients starting treatment were included in the study. Of them, the majority was male $(86 / 115 ; 74.8 \%)$ with a mean age of 48 (standard deviation (SD) \pm 12 ) years and Human Immunodeficiency Virus (HIV) negative (105/115; 91.3\%). Nearly two-thirds $(72 / 115 ; 62.6 \%)$ had XDR (extensive drug resistance) or MDR/RR-TB with additional resistance to second line injectables or fluoroquinolones. Of 115 culture-positive patients at baseline, $103(89.6 \%)$ patients achieved culture conversion during 12 months of treatment. The median time to culture conversion was 1.1 months (interquartile range: 0.9-1.8). Patients aged $\geq 60$ years compared with $<40$ years [adjusted hazard ration (aHR): $0.40,95 \%$ confidence interval (CI): 0.18-0.86], smokers (aHR: 0.39, 95\% CI: 0.2-0.73), patients with positive sputum smear microscopy at baseline (aHR: $0.40,95 \%$ CI: $0.25-$ 0.63 ), cavities on initial chest X-ray (aHR: $0.56,95 \%$ CI: 0.35 0.88 ) and resistance to at least one fluoroquinolone drug (aHR: $0.52,95 \%$ CI: $0.32-0.84$ ) were slower to culture convert. In conclusion, we recommend providing additional counselling, treatment adherence interventions and scale up the use of new and repurposed TB drugs to patient groups at risk of worse interim treatment outcome: patients aged 60 and above, with resistance to fluoroquinolones, smear-positive, smokers, or with signs of extensive disease evident on initial chest radiography.
\end{abstract}

\section{Introduction}

Tuberculosis (TB) remains one of the deadliest infectious diseases in the world [1]. Globally, it is estimated that in 201810 million people fell ill and 1.45 million died from TB [1]. 
Rifampicin Resistant TB (RR-TB) and Multidrug-Resistant TB (MDR-TB), defined as TB resistant to at least isoniazid and rifampicin, result in additional challenges for patients and national TB programmes [1]. Treatment durations is up to 2 years, frequent severe side-effects and poor treatment responses result in physical and economic hardship for patients and high costs and poor disease control for national programmes [2]. International treatment success was reported for only $56 \%$ of the patients treated for MDR/RR-TB in 2016 [1].

In recent years, global MDR/RR-TB treatment recommendations have been regularly updated following the approval of 2 new TB drugs, bedaquiline and delamanid, in 2012 and 2014 respectively. Furthermore, newer evidence proving the effectiveness of these new drugs [2,3] alongside linezolid and clofazimine (antibiotics predominantly used for other diseases) has resulted in their prioritization for MDR/RR-TB treatment in the most recent guideline update of World Health Organization (WHO) [4].

Time to culture conversion may be used as an interim predictor of MDR/RR-TB treatment success and is frequently used by practitioners to support hospital discharge planning. In a recent study of patients treated for MDR-TB, culture conversion before 2 months and 6 months of treatment was associated with treatment success. In this study 2-month conversion had low sensitivity $(26.9 \%)$ and high specificity $(91.3 \%)$ and 6-month conversion had high sensitivity $(80.7 \%)$, retaining moderate specificity for treatment success (67.6\%) [5]. Low Body Mass Index (BMI), excessive alcohol use, high sputum microscopy grade, cavitation and bilateral consolidation on chest radiography and Human Immunodeficiency Virus (HIV)-negative status have been associated with delayed time to culture conversion amongst patients treated for MDR/RR-TB [6-8]. Treatment regimens including bedaquiline, delamanid or linezolid have been associated with reduced time to culture conversion [9-11].

No previous studies have been conducted to assess determinants of time to culture conversion for MDR/RR-TB patients in Lithuania. Identifying factors associated with longer time to sputum culture conversion could aid in determining which groups of patients may benefit more from interventions, known to increase favourable treatment outcomes, such as health education and counselling on tuberculosis and treatment adherence, treatment adherence interventions and scale up the use of new and repurposed TB drugs. Reliable programmatic evidence assessing factors associated with time to culture conversion is needed to optimize national practice relating to allocation of recourses with the aim of improving patient experiences of treatment and improving treatment responses.

Our study aimed to identify factors associated with time to sputum culture conversion among all hospitalized adults starting treatment for pulmonary MDR/RR-TB at Republican Klaipeda Hospital between July 2016 and July 2019.

\section{Materials and Methods}

\section{Study design}

We conducted a cohort study based on secondary data collected from the medical records.

\section{Study setting}

Lithuania is a high-income post-soviet European Union (EU) country by the Baltic sea with 2.8 million inhabitants [12]. The incidence of MDR-TB is amongst the highest in the EU and
MDR/XDR-TB treatment results amongst the worst. In 2018 Lithuania reported TB incidence of 44/100.000, 19\% of which was MDR-TB (data from the Lithuanian Tuberculosis registry information). Only $56 \%$ of all MDR/RR-TB cases were successfully treated in 2016 in Lithuania [13]. TB diagnostic and treatment in Lithuania is free of charge.

Republican Klaipeda Hospital serves as a referral centre in Western Lithuania and provides MDR/RR-TB diagnostic and treatment services. A centralized laboratory at the hospital uses smear microscopy, Xpert MTB/RIF (Cepheid, Sunnyvale, CA, USA), MGIT 320 liquid-based culture (Becton Dickinson Microbiology Systems, Sparks, MD, USA) and LowensteinJensen (LJ) solid culture. All MDR/RR-TB patients are hospitalized and begin treatment after a local panel of experts. Second-line drug susceptibility testing (SL DST) is performed for all RR/MDR-TB patients. Patients submit sputum monthly for smear microscopy and culture on LJ media while they are in hospital. Following discharge, sputum smear and culture testing is performed every second month. During 2016, Lithuania adopted a nationwide strategy to provide directly observed therapy in ambulatory settings and gained access to bedaquiline, delamanid and linezolid. In 2018, Republican Klaipeda Hospital introduced an ambulatory video-observed treatment service.

\section{Study population}

All LJ culture-positive adult RR/MDR-TB patients, initiating treatment in Republican Klaipeda Hospital Tuberculosis Branch between $1^{\text {st }}$ July 2016 and $1^{\text {st }}$ July 2019 and receiving at least 30 days of treatment were included in the study. LJ culture positivity was defined as positive respiratory sample culture on LJ medium taken within 3 months to treatment initiation. Data recorded in clinical files was included up to $1^{\text {st }}$ February 2020.

\section{Variables}

Variables included in the analysis comprised of demographic, clinical, bacteriological and radiological characteristics, including sex, age, BMI, smoking status, harmful use of alcohol, HIV and Antiretroviral Therapy (ART) status, baseline smear grade, time to detection in liquid culture in days, affected lobe count and presence of cavities on initial chest radiography, MTB resistance type, history of previous TB treatment and drugs used in first 6 months of treatment were collected. Harmful use of alcohol was self-reported at the time of hospitalization or where alcohol was used during hospitalization. The definition of culture conversion was two consecutive negative cultures from sputum samples collected at least 30 days apart after treatment initiation [14]. Time to culture conversion was defined as the time interval between treatment initiation and the specimen collection date of the first negative culture.

\section{Data collection and analysis}

Data was collected from medical records and hospital emedicine system and entered in EpiData database created for the purpose. Entered data was cross-checked with paper-based sources. Baseline characteristics were described using frequencies and percentages for categorical variables, medians and interquartile ranges (IQRs) for continuous variables unless normally distributed where means and standard deviations were reported. Time to culture conversion was measured using the cumulative incidence function while death and loss to follow up (LTFU) were considered as competing risks. Patients were censored 12 months after treatment initiation. Hazards ratios (HR) were selected as the measure of association between factors and culture conversion. Cause- 
specific Cox regression, an extension of standard Cox model for the competing risks was applied. First, binary regressions for selected covariates were estimated. Then, variables significant at $\mathrm{p}<0.05$ in binary models were included in the final model. Age and sex as common confounders were included in the adjusted model regardless of their significance. Proportional hazard assumption was tested by using the Schoenfeld residuals against the transformed time. All selected predictors met the assumption. We calculated final treatment outcomes for a subset of patients that initiated treatment between July 2016 and December 2017. Final outcomes were categorized as successful (cured or treatment completed) and unsuccessful outcomes (death, LTFU or failure). If the final treatment outcome was not assigned and the patient was not continuing anti-TB treatment, it was classified as "not evaluated". Analysis was done using R, version 3.5.2 software ( $\left({ }^{\circ} \mathrm{R}\right.$ Foundation for Statistical Computing, 2016).

\section{Results}

\section{Baseline characteristics}

Between $1^{\text {st }}$ July 2016 and $1^{\text {st }}$ July 2019, 117 patients started treatment for pulmonary RR-TB at Republican Klaipeda Hospital, of whom $115(98 \%)$ were sputum culture positive and included in this study. The majority was male $(86 / 115 ; 74.8 \%)$, HIV-negative $(105 / 115 ; 91.3 \%)$ and sputum smear microscopy positive $(71 / 115$; $61.7 \%)$ at baseline. Most of the patients were current smokers $(91 / 115 ; 79.1 \%)$ and many exhibited harmful use of alcohol $(50 / 115 ; 43.5 \%)$. Approximately half had previously received TB treatment $(55 / 115 ; 47.8 \%)$ and resistance to second line TB drugs was detected amongst almost two thirds $(72 / 115 ; 62.6 \%)$. Half of the patients $(57 / 115 ; 50 \%)$ had fluoroquinolone resistance. The majority of patients received at least one dose of fluoroquinolone drugs $(114 / 115,99.1 \%)$, cycloserine $(111 / 114,96.5 \%)$ and prothionamide $(110 / 114,95.7 \%)$, while bedaquiline $(28 / 115,24.3 \%)$ and delamanid $(19 / 115,16.5 \%)$ were used only for selected patients. Approximately half of the patients received treatment with linezolid $(60 / 115,52.2 \%)$. Most of the patients who received bedaquiline $(17 / 29 ; 58.6 \%)$, delamanid $(15 / 19 ; 78.9 \%)$ or linezolid $(39 / 60 ; 65 \%)$ exhibited fluoroquinolone-resistance (Table 1).

\section{Time to sputum culture conversion}

Sputum culture conversion was detected in the majority of patients $(103 / 115 ; 89.6 \%)$ and all conversions occurred within the first 9 months of treatment. The median time to culture conversion was 1.1 months (95\% CI: 0.9-1.8) (Figure 1). Almost two thirds $(75 / 115 ; 65.2 \%)$ had culture converted by month 2 and almost all converted $(101 / 115 ; 87.8 \%)$ by month 6 . Eleven patients $(9.6 \%)$ died during the first 12 months of treatment with median time to death 3.1 months (IQR 1.2-8.9). Three patients $(3 / 11 ; 27.3 \%)$ culture converted prior to death.

End of treatment outcome was available for approximately half of the patients $(65 / 115 ; 56.5 \%)$. Of them, favourable treatment outcomes were recorded for 37 patients $(56.9 \%)$, while $10(15.4 \%)$ failed treatment, 3 (4.6\%) were LTFU and 14 (21.5\%) died. One patient's $(1.5 \%)$ outcome was not evaluated.

Unadjusted analysis identified associations between longer time culture conversion and smoking (HR: 0.47, 95\% CI: 0.29 0.75 ) as well as harmful alcohol use (HR: 0.56, 95\% CI 0.38-0.83). Surrogate markers of high initial bacterial load [positive baseline sputum smear (HR: $0.37,95 \%$ CI: 0.25-0.56) and presence of cav- ities on initial chest radiography (HR: $0.42,95 \%$ CI: 0.28-0.62)] were also associated with longer time to culture conversion. There was strong evidence for an association between resistance to at least one fluoroquinolone drug and longer time to culture conversion (HR: 0.51, 95\% CI: 0.34-0.77) (Figure 2). Previous TB treatment history with first line drugs (HR: $0.54,95 \%$ CI: 0.29-0.99) or second-line drugs (HR: $0.49,95 \%$ CI: $0.32-0.77$ ) was also among the risk factors of longer time to culture conversion.

In the adjusted Cox regression analysis, age 60 years or above [adjusted HR (aHR): 0.40, 95\% CI: 0.18-0.86], current smoking status (aHR 0.39 , 95\% CI $0.20-0.73$ ), positive sputum smear microscopy at baseline (aHR: 0.40, 95\% CI: 0.25-0.63), presence of cavities on initial chest radiography (aHR: $0.56,95 \% \mathrm{CI}: 0.35-$ 0.88 ) and presence of resistance to at least one fluoroquinolone drug (aHR: 0.52, 95\% CI: 0.32-0.84) were independently associated with longer time to culture conversion Table 2.

\section{Discussion}

The key findings of our study are that the median time to culture conversion was short (1.1 months, 95\% CI: 0.9-1.8) and that MDR/RR-TB treatment success was low $(37 / 64 ; 56.9 \%)$ (Table 3 ). Unsuccessful treatment outcomes were mainly due to death and treatment failure, but only half of patients who died from the causes related to TB. Most half of patients died because of TB had severe forms of the disease at admission or did not receive new and repurposed TB drugs. Additionally, we assume that low treatment success rate may be related to the fact that some of the patients who failed treatment were only receiving new and repurposed TB drugs during inpatient stage of treatment, but not in ambulatory stage.

Multiple studies have previously reported time to culture conversion as an interim predictor of MDR/RR-TB treatment response with median times ranging from 54 to 196 days, which is considerably higher than in our study [8,15-18]. Comparison of reported median times to culture conversion can be challenging due to the variation in characteristics of cohorts and testing methods. The use of LJ culture media for treatment monitoring in our study, a widely used practice in eastern European and central Asian countries, is likely to result in lower measures of time to culture conversion when compared to reports using liquid-based culture systems due to the lower sensitivity of this method [19].

We found that additional resistance to fluoroquinolones was independently associated with longer time to culture conversion. Fluoroquinolones are considered as core drugs in the newest WHO MDR/RR-TB treatment guidelines due to their potent bactericidal activity [4]. In a large individual patient data meta-analysis, their inclusion in treatment regimens was associated with approximately 4 times the odds of treatment success and half the odds of death [20]. In Lithuania, during the study period, treatment with bedaquiline, delamanid and linezolid was restricted to cases where an effective treatment regimen with at least 4 other drugs could not be constructed. As a result, most of the patients who received bedaquiline (17/29; $58.6 \%)$, delamanid $(15 / 19 ; 78.9 \%)$ or linezolid $(39 / 60 ; 65 \%)$ also exhibited fluoroquinolone-resistance. While the individual effects of these drugs were difficult to capture in this study, their well reported positive effect on MDR/RR-TB treatment response [9-11] may have resulted in under-estimation of the negative effect of fluoroquinolone resistance on time to culture conversion.

Factors corresponding to a high initial bacterial load (positive baseline smear grade and presence of cavities on initial chest radiography) were found to be associated with delayed culture conver- 
sion, a finding that has previously been described [7,21]. This finding emphasizes the importance of detecting cases early and providing effective treatment prior to the development of destructive pulmonary disease.
Age over 60 years was associated with longer time to sputum culture conversion in our study, a finding that has not been reported previously $[8,15,16]$. This association may be due to the higher prevalence of important unrecorded co-morbidities in this age

Table 1. Baseline characteristics of adult solid culture-positive pulmonary rifampicin-resistant tuberculosis patients that started treatment in Republican Klaipeda Hospital Tuberculosis Branch from July 2016 to June 2019 (n=115).

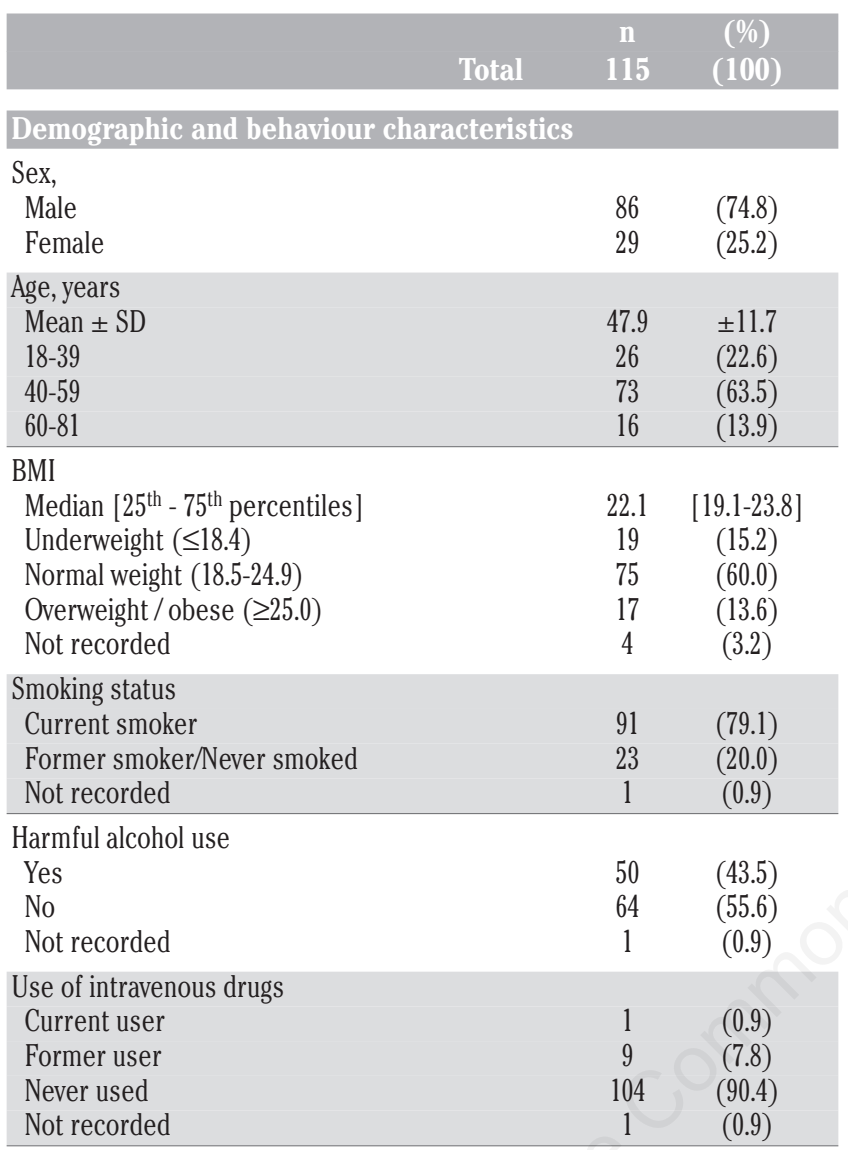

\begin{tabular}{|c|c|c|}
\hline Total & $\begin{array}{c}\mathrm{n} \\
115\end{array}$ & $\begin{array}{c}(\%) \\
(100)\end{array}$ \\
\hline Clinical characteristics & & \\
\hline $\begin{array}{l}\text { HIV status } \\
\text { HIV-positive } \\
\text { HIV-negative }\end{array}$ & $\begin{array}{c}10 \\
105\end{array}$ & $\begin{array}{c}(8.7) \\
(91.3)\end{array}$ \\
\hline $\begin{array}{l}\text { Diabetes mellitus } \\
\text { Yes } \\
\text { No }\end{array}$ & $\begin{array}{c}3 \\
112 \\
\end{array}$ & $\begin{array}{c}(2.6) \\
(97.4)\end{array}$ \\
\hline $\begin{array}{l}\text { Time to detection in liquid culture, days } \\
\text { Median }\left[25^{\text {th }}-75^{\text {th }} \text { percentiles] }\right. \\
\text { Median or below }(5-13) \\
\text { Above the median (14-37) } \\
\text { Not recorded }\end{array}$ & $\begin{array}{l}13.0 \\
47 \\
42 \\
26\end{array}$ & $\begin{array}{l}{[8.0-19.0]} \\
(40.9) \\
(36.5) \\
(22.6)\end{array}$ \\
\hline $\begin{array}{l}\text { Baseline smear grade } \\
\text { Negative } \\
\text { Positive }\end{array}$ & $\begin{array}{l}43 \\
71\end{array}$ & $\begin{array}{l}(37.4) \\
(61.7)\end{array}$ \\
\hline $\begin{array}{l}\text { Actual AFB count (1-9) } \\
1(+) \\
2(+) \\
3(+) \\
\text { Not recorded }\end{array}$ & $\begin{array}{c}19 \\
28 \\
10 \\
14 \\
1\end{array}$ & $\begin{array}{l}(16.5) \\
(24.3) \\
(8.7) \\
(12.2) \\
(0.9)\end{array}$ \\
\hline $\begin{array}{l}\text { Affected lobe count on initial chest X-ray } \\
1 \\
2 \\
3 \\
4 \\
5\end{array}$ & $\begin{array}{l}28 \\
17 \\
22 \\
19 \\
29\end{array}$ & $\begin{array}{l}(24.3) \\
(14.8) \\
(19.1) \\
(16.5) \\
(25.2)\end{array}$ \\
\hline $\begin{array}{l}\text { Presence of cavities on initial chest X-ray } \\
\text { Yes } \\
\text { No }\end{array}$ & $\begin{array}{l}61 \\
54\end{array}$ & $\begin{array}{l}(53.0) \\
(47.0)\end{array}$ \\
\hline $\begin{array}{l}\text { MTB resistance type } \\
\text { RR-TB } \\
\text { MDR-TB } \\
\text { MDR-TB + SLI } \\
\text { MDR-TB + FQ } \\
\text { XDR-TB } \\
\text { TB treatment history } \\
\text { New } \\
\text { Treated with } 1^{\text {st }} \text { line drugs } \\
\text { Treated with } 2^{\text {nd }} \text { line drugs }\end{array}$ & $\begin{array}{l}1 \\
42 \\
15 \\
17 \\
40\end{array}$ & $\begin{array}{c}(1) \\
(36.5) \\
(13.0) \\
(14.8) \\
(34.8) \\
\\
(52.2) \\
(13.9) \\
(33.9)\end{array}$ \\
\hline $\begin{array}{l}\text { Drugs used for RR-TB treatment (first } 6 \text { months) } \\
\text { Bedaquiline } \\
\text { Delamanid } \\
\text { Linezolid } \\
\text { Fluoroquinolones } \\
\text { Amikacin } \\
\text { Capreomycin } \\
\text { Cycloserine } \\
\text { Prothionamide } \\
\text { P-aminosalicylic acid } \\
\text { Pyrazinamide } \\
\text { Ethambutol }\end{array}$ & $\begin{array}{c}28 \\
19 \\
60 \\
114 \\
52 \\
66 \\
111 \\
110 \\
85 \\
55 \\
42\end{array}$ & $\begin{array}{l}(24.3) \\
(16.5) \\
(52.2) \\
(99.1) \\
(45.2) \\
(57.4) \\
(96.5) \\
(95.7) \\
(73.9) \\
(47.8) \\
(36.5)\end{array}$ \\
\hline
\end{tabular}

RR-TB, rifampicin resistant tuberculosis; SD, standard deviation; HIV, human immunodeficiency virus; ART, antiretroviral therapy; BMI, body mass index; AFB, acid-fast bacilli; MTB, Mycobacterium tuberculosis; MDRTB, multidrug resistant tuberculosis; SLI, second line injectables; FQ, fluorochinolones; XDR-TB, extensively drug resistant tuberculosis. 


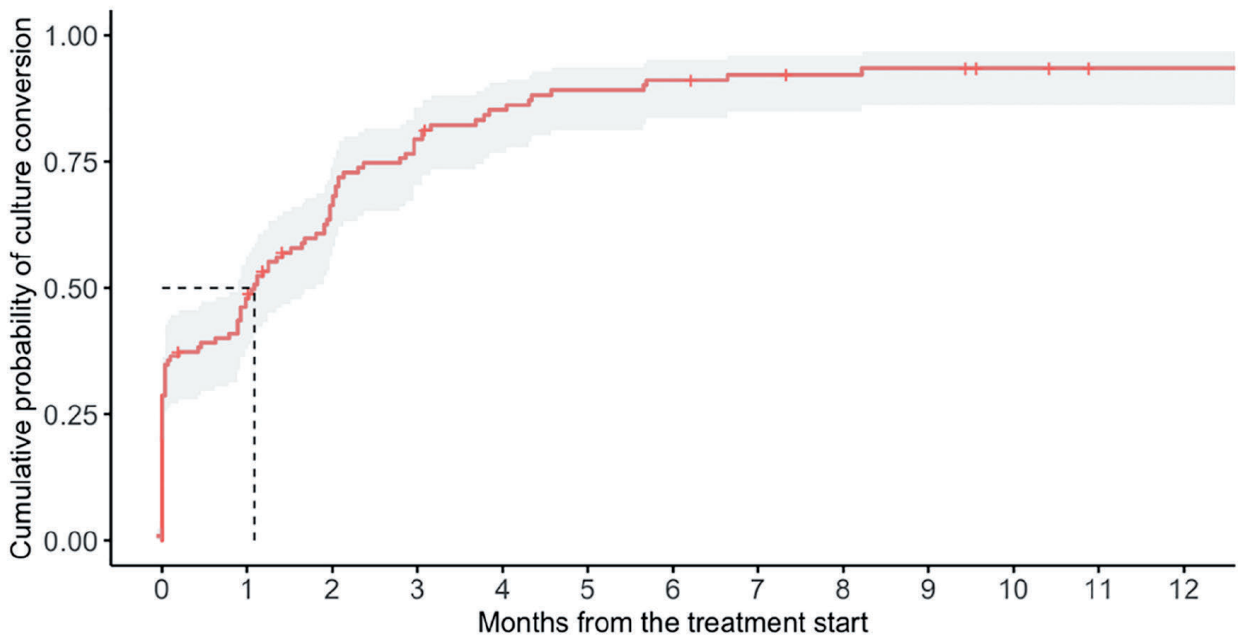

\begin{tabular}{|l|ccccccccccccc|}
\hline \multicolumn{1}{|c}{ Months } & 0 & 1 & 2 & 3 & 4 & 5 & 6 & 7 & 8 & 9 & 10 & 11 & 12 \\
\hline At risk & 115 & 59 & 36 & 22 & 15 & 11 & 9 & 7 & 6 & 5 & 3 & 1 & 1 \\
$\begin{array}{l}\text { Conversions } \\
\text { Cumulative \% of }\end{array}$ & - & 55 & 20 & 14 & 6 & 4 & 2 & 1 & - & 1 & - & - & - \\
$\begin{array}{l}\text { conversions } \\
\text { Deaths }\end{array}$ & - & 48 & 65 & 77 & 83 & 86 & 88 & 89 & 89 & 90 & 90 & 90 & 90 \\
Loss to follow up & - & 1 & 3 & 1 & 1 & - & - & 1 & 1 & 1 & 1 & 1 & - \\
\hline
\end{tabular}

Figure 1. Kaplan Meier curve of time to sputum culture conversion adjusted for the competing risk of death among adult solid culturepositive pulmonary rifampicin resistant tuberculosis patients that started treatment in Republican Klaipeda Hospital Tuberculosis Branch from July 2016 to June 2019 (n=115).

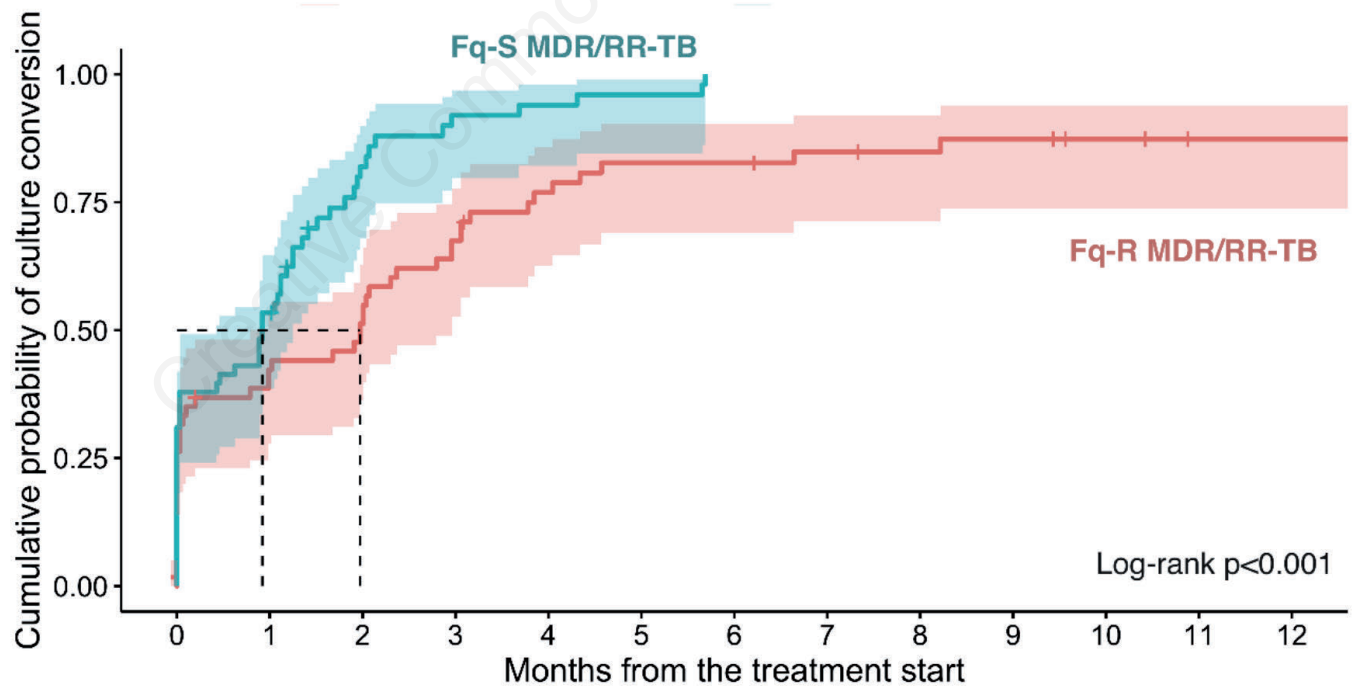

Number at risk, $\mathrm{n}$

$\begin{array}{rrrrrrrrrrrrr}-56 & 32 & 27 & 18 & 12 & 9 & 9 & 7 & 6 & 5 & 3 & 1 & 1 \\ -\quad 58 & 27 & 9 & 4 & 3 & 2 & 0 & 0 & 0 & 0 & 0 & 0 & 0\end{array}$

Figure 2. Kaplan Meier curve of time to sputum culture conversion by the type of tuberculosis resistance adjusted for the competing risk of death among adult solid culture-positive pulmonary rifampicin resistant tuberculosis patients that started treatment in Republican Klaipeda Hospital Tuberculosis Branch from July 2016 to June 2019 (n=115). Fq-S, fluoroquinolone-sensitive; Fq-R, fluoroquinolone-resistant; MDR-TB, multidrug resistant; RR, rifampicin resistant; TB, tuberculosis. 
Table 2. Factors associated with time to sputum culture conversion among adult solid culture-positive pulmonary rifampicin-resistant tuberculosis patients that started treatment in Republican Klaipeda Hospital Tuberculosis Branch from July 2016 to June 2019 $(n=115)$.

\begin{tabular}{|c|c|c|c|c|c|c|c|}
\hline Characteristics & $\begin{array}{c}\text { Culture } \\
\text { conversion } \\
\text { (n) } \\
103\end{array}$ & $\begin{array}{l}\text { Follow-up } \\
\text { time } \\
\text { (person- } \\
\text { months) } \\
214.0\end{array}$ & $\begin{array}{c}\text { Rate } \\
\text { (n/person- } \\
\text { months) } \\
0.48\end{array}$ & $\begin{array}{l}\text { Crude } \\
\text { hazard ratio } \\
(95 \% \mathrm{CI})\end{array}$ & p-value & $\begin{array}{l}\text { Adjusted } \\
\text { hazard ratio } \\
(95 \% \mathrm{CI})\end{array}$ & p-value \\
\hline $\begin{array}{l}\text { Sex } \\
\text { Male } \\
\text { Female }\end{array}$ & $\begin{array}{l}75 \\
28\end{array}$ & $\begin{array}{l}176.0 \\
37.9\end{array}$ & $\begin{array}{l}0.43 \\
0.74\end{array}$ & $\begin{array}{c}0.73(0.47-1.13) \\
\text { ref. }\end{array}$ & $\begin{array}{l}0.156 \\
\text { ref. }\end{array}$ & $\begin{array}{c}1.37(0.80-2.32) \\
\text { ref. }\end{array}$ & $\begin{array}{c}0.249 \\
\text { ref. }\end{array}$ \\
\hline $\begin{array}{l}\text { Age, years } \\
18-39 \\
40-59 \\
60-81\end{array}$ & $\begin{array}{l}23 \\
68 \\
12 \\
\end{array}$ & $\begin{array}{c}32.9 \\
145.0 \\
36.0 \\
\end{array}$ & $\begin{array}{l}0.70 \\
0.47 \\
0.33 \\
\end{array}$ & $\begin{array}{c}\text { ref. } \\
0.71(0.44-1.14) \\
0.63(0.31-1.27) \\
\end{array}$ & $\begin{array}{l}\text { ref. } \\
0.157 \\
0.196 \\
\end{array}$ & $\begin{array}{c}\text { ref. } \\
0.72(0.43-1.20) \\
0.40(0.18-0.86)\end{array}$ & $\begin{array}{r}\text { ref. } \\
0.204 \\
0.019 \\
\end{array}$ \\
\hline $\begin{array}{l}\text { BMI } \\
\text { Underweight }(\leq 18.4) \\
\text { Normal weight }(18.5-24.9) \\
\text { Overweight/obese }(\geq 25.0)\end{array}$ & $\begin{array}{l}16 \\
68 \\
17\end{array}$ & $\begin{array}{c}47.3 \\
134.0 \\
14.4\end{array}$ & $\begin{array}{l}0.34 \\
0.51 \\
1.18\end{array}$ & $\begin{array}{c}0.70(0.40-1.21) \\
\text { ref. } \\
1.68(0.99-2.87)\end{array}$ & $\begin{array}{l}0.195 \\
\text { ref. } \\
0.056\end{array}$ & $\begin{array}{l}- \\
- \\
-\end{array}$ & $\begin{array}{l}- \\
- \\
-\end{array}$ \\
\hline $\begin{array}{l}\text { Smoking status } \\
\text { Current smoker } \\
\text { Former smoker/Never smoked }\end{array}$ & $\begin{array}{l}80 \\
23\end{array}$ & $\begin{array}{l}193.0 \\
19.2 \\
\end{array}$ & $\begin{array}{l}0.41 \\
1.20\end{array}$ & $\begin{array}{c}0.47(0.29-0.75) \\
\text { ref. }\end{array}$ & $\begin{array}{c}0.002 \\
\text { ref. }\end{array}$ & $\begin{array}{c}0.39(0.20-0.73) \\
\text { ref. }\end{array}$ & $\begin{array}{c}0.003 \\
\text { ref. }\end{array}$ \\
\hline $\begin{array}{l}\text { Harmful alcohol use } \\
\text { Yes } \\
\text { No }\end{array}$ & $\begin{array}{l}42 \\
61\end{array}$ & $\begin{array}{l}134.0 \\
78.7\end{array}$ & $\begin{array}{l}0.31 \\
0.78\end{array}$ & $\begin{array}{c}0.56(0.38-0.83) \\
\text { ref. }\end{array}$ & 0.004 & $\begin{array}{c}0.75(0.47-1.20) \\
\text { ref. }\end{array}$ & 0.226 \\
\hline $\begin{array}{l}\text { Use of intravenous drugs } \\
\text { Current user } \\
\text { Former user } \\
\text { Never used }\end{array}$ & $\begin{array}{c}1 \\
6 \\
96\end{array}$ & $\begin{array}{c}0.0 \\
26.9 \\
186.0\end{array}$ & $\begin{array}{l}\mathrm{NA} \\
0.22 \\
0.52\end{array}$ & $\begin{array}{l}- \\
0.51(0.22-1.16) \\
\text { ref. }\end{array}$ & $\begin{array}{l}- \\
0.108 \\
\text { ref. }\end{array}$ & - & - \\
\hline $\begin{array}{l}\text { HIV status } \\
\text { HIV-positive } \\
\text { HIV-negative }\end{array}$ & $\begin{array}{c}7 \\
96\end{array}$ & $\begin{array}{c}24.9 \\
189.0\end{array}$ & $\begin{array}{l}0.28 \\
0.51\end{array}$ & $\begin{array}{c}0.65(0.30-1.41) \\
\text { ref. }\end{array}$ & $\begin{array}{c}0.277 \\
-\end{array}$ & $\begin{array}{l}- \\
-\end{array}$ & - \\
\hline $\begin{array}{l}\text { Diabetes mellitus } \\
\text { Yes } \\
\text { No }\end{array}$ & $\begin{array}{c}0 \\
103\end{array}$ & $\begin{array}{c}21.5 \\
192.0\end{array}$ & $\begin{array}{l}0.00 \\
0.54\end{array}$ & $\begin{array}{l}\text { NA } \\
\text { ref. }\end{array}$ & $\begin{array}{l}\mathrm{NA} \\
\text { ref. }\end{array}$ & - & - \\
\hline $\begin{array}{l}\text { Baseline smear grade } \\
\text { Negative } \\
\text { Positive }\end{array}$ & $\begin{array}{l}41 \\
61\end{array}$ & $\begin{array}{c}30.0 \\
184.0\end{array}$ & $\begin{array}{l}1.37 \\
0.33\end{array}$ & $\begin{array}{c}\text { ref. } \\
0.37(0.25-0.56)\end{array}$ & $<0.001$ & $0.40(0.25-0.63)$ & $<0.001$ \\
\hline $\begin{array}{l}\text { Presence of cavities on initial chest X-ray } \\
\text { Yes } \\
\text { No }\end{array}$ & $\begin{array}{l}53 \\
50\end{array}$ & $\begin{array}{c}169.0 \\
45.1\end{array}$ & $\begin{array}{l}0.31 \\
1.11\end{array}$ & $\begin{array}{c}0.42(\mathbf{0 . 2 8 - 0 . 6 2}) \\
\text { ref. }\end{array}$ & $\begin{array}{l}<0.001 \\
\text { ref. }\end{array}$ & $\begin{array}{c}0.56 \text { (0.35-0.88) } \\
\text { ref. }\end{array}$ & $\begin{array}{c}\mathbf{0 . 0 1 3} \\
\text { ref. }\end{array}$ \\
\hline $\begin{array}{l}\text { MTB resistance type } \\
\text { RR-TB / MDR-TB / MDR-TB + SLI } \\
\text { MDR-TB + FQ / XDR-TB }\end{array}$ & $\begin{array}{l}55 \\
48\end{array}$ & $\begin{array}{c}63.7 \\
150.0\end{array}$ & $\begin{array}{l}0.86 \\
0.32\end{array}$ & $\begin{array}{c}\text { ref. } \\
\mathbf{0 . 5 1}(\mathbf{0 . 3 4 - 0 . 7 7 )}\end{array}$ & $\begin{array}{l}\text { ref. } \\
\mathbf{0 . 0 0 1}\end{array}$ & $\begin{array}{c}\text { ref. } \\
\mathbf{0 . 5 2}(0.32-0.84)\end{array}$ & $\begin{array}{l}\text { ref. } \\
\mathbf{0 . 0 0 8}\end{array}$ \\
\hline $\begin{array}{l}\text { TB treatment history } \\
\text { New } \\
\text { Treated with } 1^{\text {st }} \text { line drugs } \\
\text { Treated with } 2^{\text {nd }} \text { line drugs }\end{array}$ & $\begin{array}{l}56 \\
13 \\
34\end{array}$ & $\begin{array}{c}66.4 \\
34.3 \\
113.0\end{array}$ & $\begin{array}{l}0.84 \\
0.38 \\
0.30\end{array}$ & $\begin{array}{c}\text { ref. } \\
0.54(0.29-0.99) \\
0.49(0.32-0.77)\end{array}$ & $\begin{array}{c}\text { ref. } \\
\mathbf{0 . 0 4 6} \\
\mathbf{0 . 0 0 2}\end{array}$ & $\begin{array}{c}\text { ref. } \\
0.75(0.38-1.46) \\
0.63(0.38-1.04)\end{array}$ & $\begin{array}{l}\text { ref. } \\
0.395 \\
0.072\end{array}$ \\
\hline $\begin{array}{l}\text { Drugs used for RR-TB treatment (first } 6 \mathrm{~m} \\
\text { Bedaquiline } \\
\text { Delamanid } \\
\text { Linezolid } \\
\text { Fluorochinolones } \\
\text { Amikacin } \\
\text { Capreomycin } \\
\text { Cycloserine } \\
\text { Prothionamide } \\
\text { P-aminosalicylic acid } \\
\text { Pyrazinamide } \\
\text { Ethambutol }\end{array}$ & $\begin{array}{c}28 \\
19 \\
60 \\
102 \\
48 \\
58 \\
100 \\
98 \\
78 \\
45 \\
37\end{array}$ & $\begin{array}{c}40.7 \\
37.3 \\
97.5 \\
211.0 \\
94.5 \\
135.0 \\
211.0 \\
208.0 \\
164.0 \\
121.0 \\
59.1\end{array}$ & $\begin{array}{l}0.69 \\
0.51 \\
0.62 \\
0.48 \\
0.51 \\
0.43 \\
0.47 \\
0.47 \\
0.48 \\
0.37 \\
0.63\end{array}$ & $\begin{array}{l}1.28(0.82-1.98) \\
0.91(0.55-1.50) \\
1.25(0.84-1.86) \\
1.37(0.19-9.87) \\
1.08(0.73-1.60) \\
0.92(0.62-1.36) \\
0.61(0.19-1.96) \\
0.71(0.29-1.77) \\
1.03(0.65-1.61) \\
0.72(0.49-1.07) \\
1.25(0.83-1.87)\end{array}$ & $\begin{array}{l}0.278 \\
0.708 \\
0.280 \\
0.754 \\
0.692 \\
0.683 \\
0.410 \\
0.467 \\
0.915 \\
0.107 \\
0.286\end{array}$ & $\begin{array}{l}- \\
- \\
- \\
- \\
- \\
- \\
- \\
- \\
- \\
- \\
-\end{array}$ & $\begin{array}{l}- \\
- \\
- \\
- \\
- \\
- \\
- \\
- \\
- \\
- \\
-\end{array}$ \\
\hline
\end{tabular}

Missing data was excluded during hypothesis testing. Bold indicates statistically significant associations $(\mathrm{p}<0.05)$. Harmful alcohol use is defined as either harmful use of alcohol reported in the past or use of alcohol during treatment. NA, not applicable (zero cases in the comparison group or missing data); RR-TB, rifampicin resistant tuberculosis; CI, confidence interval; SD, standard deviation; HIV, human immunodeficiency virus; ART, antiretroviral therapy; BMI, body mass index; IQR, interquartile range; AFB, acid-fast bacilli; MTB, Mycobacterium tuberculosis; MDR-TB, multidrug resistant tuberculosis; SLI, second line injectables; FQ, fluorochinolones; XDR-TB, extensively drug resistant tuberculosis. 
group. We found that smoking was independently associated with longer time to culture conversion, a finding that has been previously described [16,21]. Smoking is known to negatively affect the phagocytic function of alveolar macrophage resulting in inadequate pulmonary immune responses and wider spread of TB infection [21,22]. Similar to the study from Yihunie Akalu et al., we found a crude association between self-reported harmful use of alcohol and longer time to sputum culture conversion [7]. However, after adjusting for other factors, no evidence of an association remained. This can be explained by the fact that harmful use of alcohol was overlapping with other detected factors associated with time to sputum conversion, such as: male sex, positive smoking status, and higher severity of TB disease. This finding reflects the complex mechanism underlying the association between addiction and health outcomes [23].

Our study had several strengths: our database included all patients treated at the hospital and corresponding with inclusion criteria and study period. The study was carried out under routine conditions, meaning that the data were representative of the realworld situation. The variables and measurements collected within the study were well standardized and defined. Missing data was kept at minimal, far below generally accepted $10 \%$ threshold.

The retrospective single site study design limits the generalizability of our findings. However, since TB clinical practice across eastern Europe and central Asia has many similarities, findings are likely to be applicable to countries beyond the Baltic states. When evaluating the effectiveness of treatment regimens, the use of interim rather than final outcomes remains a limitation despite their previous validation [5]. By choosing to describe final treatment outcomes alongside interim outcomes, this study was able to report more recent and likely more relevant experience from a treatment cohort. Furthermore, since this study relates to a period when newer TB drugs were introduced into routine clinical practice in Lithuania, restrictions on their use are likely to have introduced bias in the allocation of treatment particularly based on patient age and the presence of more advanced drug resistance.

Nevertheless, this was a first study that evaluates factors associated with time to sputum culture conversion for MDR/RR-TB patients in Lithuania. Identifying these factors allows for better allocation of programme resources towards those identified at greatest risk of poor treatment outcome.

Table 3. Final treatment outcomes for solid culture-positive pulmonary rifampicin resistant tuberculosis patients that started treatment in Republican Klaipeda hospital Tuberculosis branch from July 2016 to December $2017(n=65)$.

\begin{tabular}{lcc} 
Characteristics & $\mathbf{n} / \mathbf{N}$ & $\%$ \\
Treatment outcome evaluated & $64 / 65$ & 98 \\
Treatment Success & $37 / 64$ & 58 \\
\hline Cured & $36 / 64$ & 56 \\
Treatment completed & $1 / 64$ & 2 \\
\hline Unsuccessful outcome & $27 / 64$ & 42 \\
Treatment failed & $10 / 64$ & 16 \\
\hline Died & $14 / 64$ & 22 \\
Lost to follow-up & $3 / 64$ & 4 \\
\hline
\end{tabular}

\section{Conclusions}

The results of our study generate evidence for clinicians and policymakers in Lithuania that suggests the need to provide additional interventions, known to increase favorable treatment outcomes, such as health education and counseling on tuberculosis and treatment adherence, treatment adherence interventions and scale up the use of new and repurposed drugs to patient groups at risk of worse interim treatment outcome: patients aged 60 and above, with resistance to fluoroquinolones, smear-positive, smokers, or with signs of extensive disease evident on initial chest radiography. By offering more potent treatment and allocating more resources towards those at highest risk of inadequate treatment response, we are likely to see future improvements in MDR/RR-TB treatment success in Lithuania.

\section{References}

1. WHO. Global tuberculosis report 2019. Geneva: World Health Organization; 2019. Accessed on: 2019 Nov 21. Available from: https://www.who.int/tb/publications/global report/en/

2. Migliori GB, Tiberi S, Zumla A, et al. MDR/XDR-TB management of patients and contacts: Challenges facing the new decade. The 2020 clinical update by the Global Tuberculosis Network. Int J Infect Dis 2020;92:S15-25.

3. Borisov SE, Dheda K, Enwerem M, et al. Effectiveness and safety of bedaquiline containing regimens in the treatment of MDR- and XDR-TB: A multicentre study. Eur Respir J 2017;49:1700387.

4. WHO. Consolidated Guidelines on Tuberculosis, Module 4: Treatment - Drug-Resistant Tuberculosis Treatment. Geneva: World Health Organization; 2020. Accessed on 2020 Aug 7. Available from: https://www.who.int/publications/i/item/ 9789240007048

5. Bastard M, Sanchez-Padilla E, Hayrapetyan A, et al. What is the best culture conversion prognostic marker for patients treated for multidrug-resistant tuberculosis? Int J Tuberc Lung Dis 2019;23:1060-7.

6. Velayutham B, Nair D, Kannan T, et al. Factors associated with sputum culture conversion in multidrugresistant pulmonary tuberculosis. Int J Tuberc Lung Dis 2016;20:1671-6.

7. Yihunie Akalu T, Fentahun Muchie K, Alemu Gelaye K. Time to sputum culture conversion and its determinants among Multi-drug resistant Tuberculosis patients at public hospitals of the Amhara Regional State: A multicenter retrospective follow up study. PLoS One 2018;13:e0199320.

8. Shibabaw A, Gelaw B, Wang SH, Tessema B. Time to sputum smear and culture conversions in multidrug resistant tuberculosis at university of Gondar hospital, northwest Ethiopia. PLoS One 2018;13:e198080.

9. Tang S, Yao L, Hao X, et al. Efficacy, safety and tolerability of linezolid for the treatment of XDR-TB: A study in China. Eur Respir J 2015;45:161-70.

10. Gler MT, Skripconoka V, Sanchez-Garavito E, et al. Delamanid for multidrug-resistant pulmonary tuberculosis. N Engl J Med 2012;366:2151-60.

11. Diacon AH, Pym A, Grobusch MP, et al. Multidrug-resistant tuberculosis and culture conversion with bedaquiline. N Engl J Med 2014;371:723-32.

12. Official Statistics Portal [Internet]. Statistical factors analysis 
of Lithuania. Available from: https://osp.stat.gov.lt/statistiniurodikliu-analize?indicator $=$ S3R166\#/

13. WHO. Lithuania, WHO tuberculosis profile. Geneva: World Health Organization. Available from: https://www.who.int/tb/ country/data/profiles/en/

14. WHO. Definitions and reporting framework for tuberculosis. Geneva: World Health Organization; 2015. Available from: https://www.who.int/tb/publications/definitions/en/

15. Liu Q, Lu P, Martinez L, et al. Factors affecting time to sputum culture conversion and treatment outcome of patients with multidrug-resistant tuberculosis in China. BMC Infect Dis 2018;18:114.

16. Qazi F, Khan U, Khowaja S, et al. Predictors of delayed culture conversion in patients treated for multidrug-resistant tuberculosis in Pakistan. Int J Tuberc Lung Dis 2011;15:1556-9.

17. Lu P, Liu Q, Martinez L, et al. Time to sputum culture conversion and treatment outcome of patients with multidrug-resistant tuberculosis: A prospective cohort study from urban China. Eur Res J 2017;49.

18. Guglielmetti L, Le Dû D, Jachym M, et al. Compassionate use of bedaquiline for the treatment of multidrug-resistant and extensively drug-resistant tuberculosis: Interim analysis of a French cohort. Clin Infect Dis 2014;60:188-94.

19. Rishi S, Sinha P, Malhotra B, Pal N. A comparative study for the detection of mycobacteria by BACTEC MGIT 960, Lowenstein Jensen media and direct AFB smear examination. Indian J Med Microbiol 2007;25:383-6.

20. Ahmad N, Ahuja SD, Akkerman OW, et al. Treatment correlates of successful outcomes in pulmonary multidrug-resistant tuberculosis: an individual patient data meta-analysis. Lancet 2018;392:821-34.

21. Salindri AD, Kipiani M, Kempker RR, et al. Diabetes reduces the rate of sputum culture conversion in patients with newly diagnosed multidrug-resistant tuberculosis. Open Forum Infect Dis 2016;3:ofw126.

22. Lin HH, Ezzati M, Chang HY, Murray M. Association between tobacco smoking and active tuberculosis in Taiwan: Prospective cohort study. Am J Respir Crit Care Med 2009;180:475-80.

23. Raviglione M, Poznyak V. Targeting harmful use of alcohol for prevention and treatment of tuberculosis: A call for action. Eur Res J 2017;50:1700946. 